\title{
Assessment of Pain Perception of Elderly Patients with Different Levels of Dentophobia during Surgical Dental Appointment
}

\author{
A. V. Sevbitov, A. E. Dorofeev, A. A. Davidiants, K. A. Ershov, A. V. Timoshin \\ Department of Propaedeutics of Dental Diseases, Sechenov University, Moscow, Russia
}

\begin{abstract}
Context: Elderly patients constitute a significant proportion of the population. All of them need skilled dental care. However, a significant proportion of patients is afraid of dental appointment. Premedication before a dental treatment is shown for all patients with a high level of anxiety. However, during studying the medical records of each patient, the significant number of comorbidities is identified which limit us in the use of medications for the prevention of stress and pain at the dental appointment. Aims: The aim of this study is to improve the quality of surgical dental care for elderly patients living in a gerontological center with different levels of dentophobia. This study evaluated the perception of pain of elderly patients with middle and high level of a dentophobia on surgical dental appointment. Materials and Methods: All patients, who participated in the study, live in geriatric center. All patients before surgery tooth extraction took the advice of a psychiatrist and neurologist. Patients with a high level of a dentophobia were held premedication over-the-counter medication and local anesthesia with a solution of $4 \%$ articaine with vasoconstrictor in a dilution of 1:200000. Premedication was not conducted for patients with middle level of dentophobia, and local anesthesia for them was done using 3\% mepivacaine solution without vasoconstrictor. Evaluation of pain perception was carried out by the following methods: Electroodonto diagnosis, electromyography of facial muscles, sound eyes motor scale, and the visual analog scale. All the results obtained were processed in the program Statistical 6.0. Results: The results obtained using these methods have shown a reliable correlation between each other. Conclusions: The efficiency of premedication was proven as reducing the perception of pain of patients with high level of dentophobia.
\end{abstract}

Key words: Dentistry, dentophobia, elderly age, gerontology, local anesthesia, pain

\section{INTRODUCTION}

I $n$ modern medicine and in particular in dentistry, the problem of pain now plays a leading role. This is because pain syndrome is one of the most common in most human diseases. However, the pain in the maxillofacial region has its own peculiarities. The tissues of the oral cavity, in comparison with other organs, are very richly innervated by nerve endings, which affects the greater sensitivity of this area. In this area, four pairs of cranial nerves are represented: The trigeminal, laryngopharyngeal, sublingual, and vagus nerve. In this regard, the maxillofacial region is a powerful reflexogenic zone. The study of pain is one of the most difficult problems. Patients differently report the localization, nature, duration, and strength of their painful sensations. ${ }^{[1-4]}$

In a number of studies, the relationship between duration and strength of pain sensations with psychological factors has been revealed. Excitation, fear, and depression lead to inadequate treatment of pain: In one case, patients can exaggerate the power of pain, and others underestimate. Difficulties arising in patients describing their condition complicate the diagnosis, especially if the pain is psychogenic. ${ }^{[5-7]}$ Individual perception of pain is influenced by demographic factors, sex, age, and ethnic characteristics. According to some studies, women more often than men complain of a variety of temporary and recurrent pain and note a stronger, more frequent, and longer pain. Features of conducting outpatient dental interventions contribute to the

Address for correspondence:

A. E. Dorofeev, Department of Propaedeutics of Dental

Diseases, Sechenov University, Moscow, Russia.

E-mail: aedorofeev88@gmail.com

Received: 06-09-2018

Revised: 21-09-2018

Accepted: 27-09-2018 
emergence of severe emotional stress in patients. The majority (96\%) of outpatient dental interventions is performed with the patients' consciousness preserved, which is necessary for proper treatment, but contributes to aggravation of perception of psychotraumatic factors during treatment. Preserved consciousness is the basis for the emergence of negative reactions to the appearance and sound of the drill, to specific medicinal odors, and dental instruments. This causes different emotional states from mild fright to indescribable horror, which can affect the strength and character of the perception of pain. ${ }^{[8-11]}$ The known methods of subjective assessment of pain are verbal-sign-visual-analog, rating scales or questionnaires, for example, the McGillovsky questionnaire. However, at the moment, there is almost no rapid pain assessment test that allows without a long time in sufficient degree assessment of the patients' condition for the selection of adequate analgesic therapy in the postoperative period. To date, there has been no assessment of the perception of pain in elderly and senile patients living in a gerontological center, with different psychoemotional status in outpatient surgical dental reception and in the postoperative period. ${ }^{[12-14]}$

\section{MATERIALS AND METHODS}

The work was done at Sechenov University with the support of the 5 top 100 program. Ethical examination was passed in the local Ethics Committee of the Sechenov University. The study involved 91 patients aged 75-85 years living in a gerontological center. Before the study, patients were introduced to the design of the proposed work, informed of possible complications, and written consent about participating in the study was received from each patient.

Patients were divided into two groups: Group 1 included 27 men and 35 women with an average level of dentophobia, and Group 2 included 11 men and 18 women with high level of dentophobia.

Criteria for inclusion of patients in the study are as follows: The presence of written informed consent of the patient to participate in the study, presence of the signed informed consent to the tooth extraction operation, patients' age is 75-85 years, absence of sub-and decompensated neurological and mental diseases, and presence of indications of the operation of tooth extraction on the upper jaw. Criteria for non-inclusion of patients in the study are as follows: Inappropriate age group, the presence of sub- and decompensated neurological and mental diseases, and other types of outpatient surgery. The criteria for excluding patients from the study are as follows: The patients' refusal to continue to participate in the study, the transferred sub- and decompensated neurological and mental illness, violation of the doctor's recommendations, and changing of the living place.
The level of dentophobia was determined using the Modified Dental Anxiety Scale. All the patients had an operation to remove the tooth for periodontal indications on the teeth of the upper jaw.

The method of infiltration with 3\% mepivacaine solutions without a vasoconstrictor in patients with an average anxiety level and a solution of $4 \%$ articaine with a vasoconstrictor 1: 200,000 in patients with a high level of anxiety was used as an anesthesia. The volume of anesthetic injected averaged $1.5 \mathrm{ml}$.

Before the operation of tooth extraction, all patients underwent consultations with the attending physician, psychiatrist, and neurologist. Patients with a high level of anxiety were subjected to an additional correction of their emotional state with the MigStress of Evalar, to reduce pain sensitivity during the operation.Composition of the preparation: 1. Glycine is an amino acid necessary for the central nervous system. Stimulates the processes of excitation and inhibition in the central nervous system, increases mental efficiency, helps to eliminate depressive conditions, increased irritability. Promotes healthy sleep. 2. Passionflower improves overall performance, helps the body to resist stress and to cope with physical and emotional overloads, and has a calming effect. Applicable with increased excitability. 3. Gryphonium is a bush of the bean family, native to West Africa. Passionflower improves overall performance, helps the body to resist stress and to cope with physical and emotional overloads, and has a calming effect. Applicable with increased excitability; gryphonium is a bush of the bean family, native to West Africa. Active substances are derivatives of tryptophan. Gryphonium promotes the production of the hormone serotonin, which plays an important role in the body, soothingly affects the nervous system, improves mood, regulates appetite, and improves sleep. It is prescribed for depression, insomnia, migraine, and anxiety. The maximum daily dose is 4 tablets. The patient was asked to dissolve one tablet before the operation. Patients with an average level of anxiety did not undergo pharmacological correction of the psycho-emotional state.

To assess the pain during the operation, the following methods were used: Electrodontodiagnosis, electromyography of facial muscles, Sound Eye Motor Scale, and a visual analog scale. Before conducting anesthesia, an electrodontodiagnosis of the tooth to be removed was performed using the IVN-01 apparatus PULPTEST-PRO. For the norm, the electroexcitability of the pulp was taken from $2 \mu \mathrm{A}$ to $6 \mu \mathrm{A}$. The study was repeated on the same teeth 2 and 4 min after local anesthesia.

Electromyography was carried out in the following way: All patients before surgery were fixed a cutaneous electrode at the nose bridge to fix the bioelectric activity of musculus procerus. During the operation of removing the tooth, the motor skills of the patient were recorded, which indirectly indicated pain. All the data were recorded in a special table of 
Table 1: The distribution of patients by groups depending on the level of anxiety, local anesthesia, and adherence

\begin{tabular}{|c|c|c|c|c|}
\hline \multirow{3}{*}{$\begin{array}{l}\text { Group } \\
\text { Level of anxiety } \\
\text { Gender }\end{array}$} & \multicolumn{2}{|c|}{ Group 1} & \multicolumn{2}{|c|}{ Group 2} \\
\hline & \multicolumn{2}{|c|}{ Average anxiety } & \multicolumn{2}{|c|}{ High anxiety } \\
\hline & Men & Women & Men & Women \\
\hline Number of people & 27 & 35 & 11 & 18 \\
\hline Local anesthetic & \multicolumn{2}{|c|}{$\begin{array}{l}\text { Mepivacaine } 3 \% \text { without } \\
\text { vasoconstrictor }\end{array}$} & \multicolumn{2}{|c|}{ Articaine $4 \%$ with vasoconstrictor $1: 200000$} \\
\hline Premedication & \multicolumn{2}{|c|}{ Not conducted } & \multicolumn{2}{|c|}{ MigStress } \\
\hline
\end{tabular}

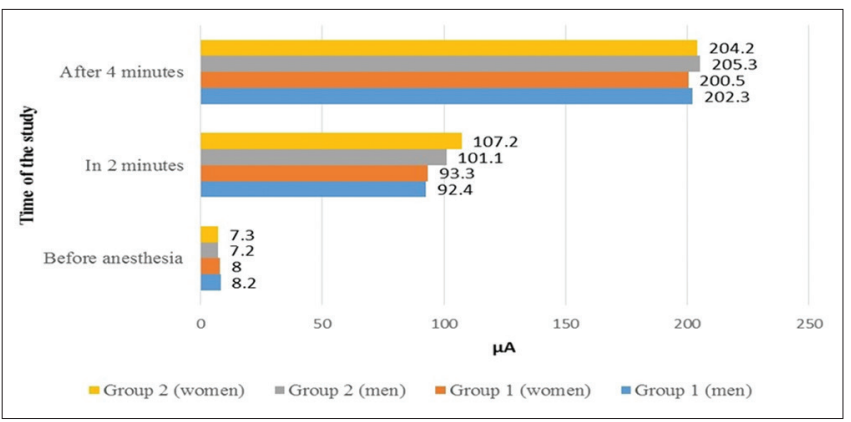

Figure 1: Dynamics of electroexcitability of pulp before and after anesthesia in the patients under study

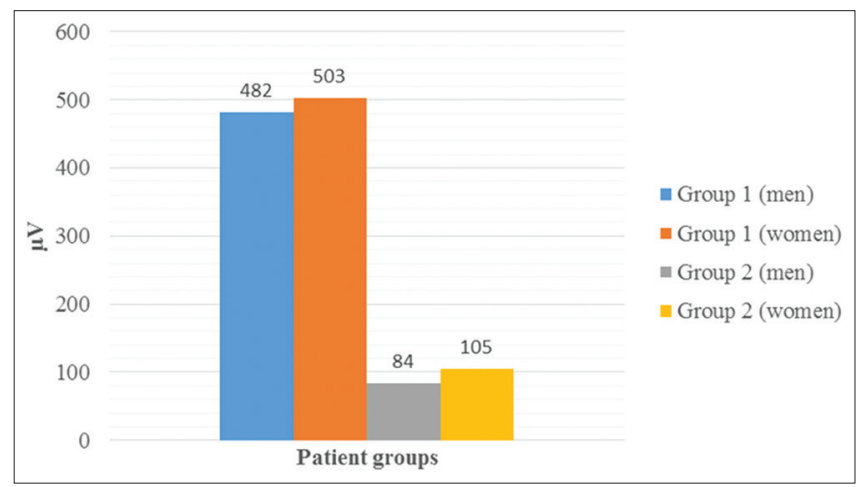

Figure 2: Indicators of bioelectrical activity of facial muscles in patients of the study groups during the operation of tooth extraction

the Sound Eye Motor Scale, after which the sum of the scores was displayed, indicating the degree of discomfort the patient experienced. At values from 0 to 3, the patient experienced minor discomfort, with a score of 4-6 moderate pain, and 7-9 severe pain. Patients of both the groups after the tooth extraction operation were examined using visual analog scale, where it was necessary to assess their pain during the operation in the range from 0 to 10 points, where 1 - no pain and 10 - the strongest possible pain. All the results obtained were processed in the program Statistical 6.0.

\section{RESULTS AND DISCUSSION}

After determining the level of dental anxiety, patients were divided into groups [Table 1]. The arithmetic mean of the indicators of electroodontodiagnostics before anesthesia in Group 1 was $8.0 \pm 0.53 \mu \mathrm{A}$ for women and $8.2 \pm 0.42 \mu \mathrm{A}$ for men. In Group 2, the indices were slightly lower and amounted to $7.3 \pm 0.38 \mu \mathrm{A}$ for women and $7.2 \pm 0.48 \mu \mathrm{A}$ for men.

2 min after the local anesthesia in Group 1 patients, the electrical excitability of the pulp increases to $93.3 \pm 0.29 \mu \mathrm{A}$ for women and $92.4 \pm 0.41 \mu \mathrm{A}$ for men, while in patients in Group 2, the following were 107.2 $\pm 0.43 \mu \mathrm{A}$ for women and $101.1 \pm 0.32 \mu \mathrm{A}$ for men.

In the third study, 4 min after the local anesthesia in Group 1 patients, the average electromotive excitability of the pulp was $200.5 \pm 1.32 \mu \mathrm{A}$ for women and $202.3 \pm 1.21$ $\mu \mathrm{A}$ for men. In patients in Group 2, the results were similar and amounted to $204.2 \pm 0.85 \mu \mathrm{A}$ for women and $205.3 \pm$ $0.92 \mu \mathrm{A}$ for men [Figure 1].

When comparing the pulp response of the patients with different levels of anxiety, it can be noted that, for patients with a high level of anxiety, the threshold of electrical excitability of the pulp is slightly lower than for patients with an average level of anxiety. ${ }^{[15,16]}$

After anesthesia, the groups were compared with each other. It can be noted that, for patients who underwent anesthesia with a solution of $4 \%$ articaine with a vasoconstrictor at a dilution of 1:200,000 compared to the patients who underwent anesthesia with a $3 \%$ mepivacaine solution without a vasoconstrictor, anesthesia occurred slightly faster. It is reflected in the results obtained after $2 \mathrm{~min}$ after the local anesthesia. This can be explained by the greater bioavailability of a $4 \%$ solution of articaine. However, after $4 \mathrm{~min}$, the results were equalized, which made it possible to do a tooth extraction operation painlessly in both cases. As well as the sedative MigStress, which allowed to level the pain in both groups, came about. The obtained results testified to the onset of adequate anesthesia, which was used for the psychocorrection of the patient's condition to reduce the emotional stress. ${ }^{[17]}$

When studying the bioelectrical activity of the facial muscle, the following results were obtained ${ }^{[18]}$ Patients of Group 1 were noted by considerable activity musculus procerus that 


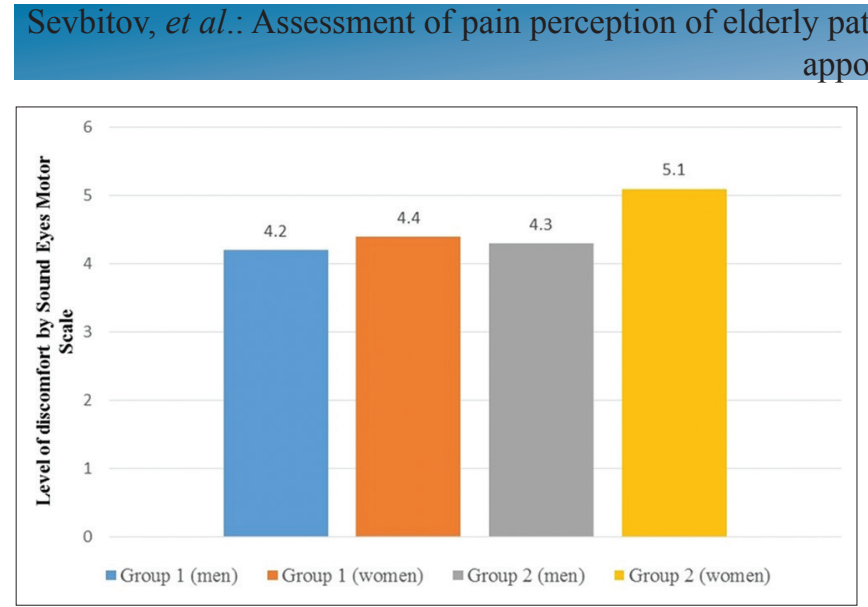

Figure 3: Indicators of the level of discomfort of patients in the study groups obtained with the help of Sound Eye Motor Scale

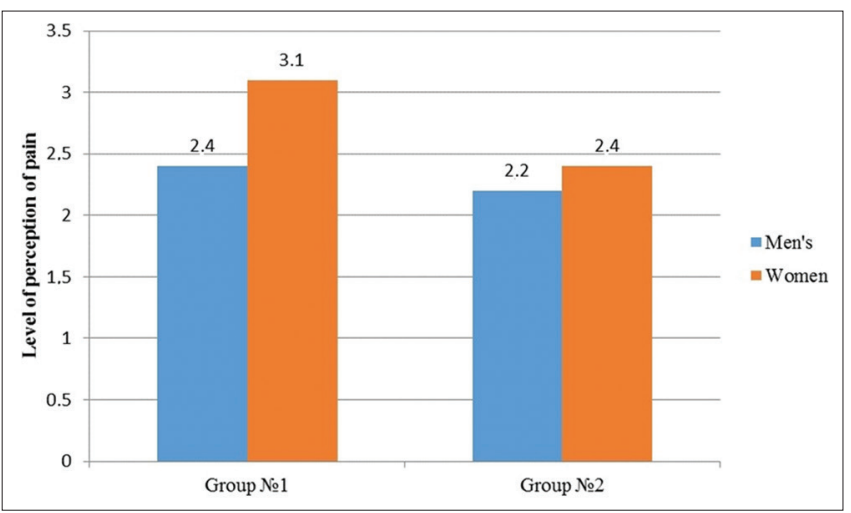

Figure 4: The level of perception of pain in patients obtained using a visual analog scale

speaks about its active reduction during operation of a tooth extraction. This may indicate some discomfort that the patient experienced during the operation. ${ }^{[19-21]}$ Group 2 patients who received premedication showed minimal activity in the contraction of this muscle, which indicates their calmness during surgery [Figure 2].

When analyzing the level of discomfort with the help of Sound Eye Motor Scale in Group 1, it can be noted that it averaged $4.4 \pm 2.13$ in women and $4.2 \pm 1.25$ in men. These figures indicate a moderate discomfort experienced by patients during the operation. In Group 2 patients, the indices were close to patients with an average anxiety level of 5.1 \pm 1.36 in women and $4.3 \pm 2.24$ in men. When comparing patients of the two groups, it can be noted that there are no significant differences between patients with different levels of anxiety, which indicates the positive effect of the premedication used by us. For patients with a high level of anxiety, there is a slightly higher level of discomfort - various hand movements, facial expressions, anxiety in the eyes, nonspecific sounds, but they are not clinically significant, ${ }^{[2]}$ within the limits of the figures obtained [Figure 3].

After the operation for patients of Group 1 on the visual analog scale noted values close to minimal pain, these values averaged $3.1 \pm 0.63$ for women and $2.4 \pm 1.35$ for men patients. In Group 2 patients, the values were slightly lower and were $2.4 \pm 1.62$ for women and $2.2 \pm 1.14$ for men. This can be explained both by the action of premedication and by a stronger local anesthetic performed by a solution of $4 \%$ articaine with a vasoconstrictor at a dilution of 1:200,000 [Figure 4]. In both the groups, regardless of the level of anxiety, female patients on average had a slightly higher incidence of pain than male patients [Figure 4].

\section{CONCLUSION}

All patients with a high level of dentophobia before a dental intervention need a consultation of a psychiatrist and neurologist. The results of the pain assessment showed the effectiveness of the MigStress applied by us, which affected the lower pain sensations of patients in the group with a high level of anxiety. Furthermore, there was a greater efficacy of a solution of $4 \%$ articaine with a vasoconstrictor in a 1:20000 dilution as a local anesthetic was shown.

\section{REFERENCES}

1. Ershov KA, Sevbitov AV, Dorofeev AE, Pustokhina IG. Evaluation of elderly patients adaptation to removable dentures. Indo Am J Pharm Sci 2018;5:1638-41.

2. Kuznetsova M, Nevdakh AS, Platonova VV, Sevbitov AV, Dorofeev AE. Evaluation of effectiveness of a preparation on the basis of phytoecdysteroids for treatment of traumatic injuries of oral mucosa in orthodontic patients. Int J Green Pharm 2018;12S1:297-300.

3. Sevbitov AV, Yu LV, Yu KE, Drobot GV, Platonova VV, Dorofeev AE. Analysis of the perception of pain of elderly patients during surgical dental appointment. Int Dent J 2017;67S1:64.

4. Yumashev AV, Gorobets TN, Admakin OI, Kuzminov GG, Nefedova IV. Key aspects of adaptation syndrome development and anti-stress effect of mesodiencephalic modulation. Indian J Sci Technol 2016;9:93911.

5. YumashevAV,UtyuzhAS, VolchkovaIR, Mikhailova MV, Kristal EA. The influence of mesodiencephalic modulation on the course of postoperative period and Osseo integration quality in case of intraosseus dental implantation. Indian J Sci Technol 2016;9:104307.

6. Timoshin AV, Sevbitov AV, Drobot GV, Yumashev AV, Timoshina MD. Use of bioresorbable plates on the basis of collagen and digestase for treatment of diseases of oral mucosa (review of clinical cases). Int J Green Pharm 2018;12S1:290-6.

7. Timoshin AV, Sevbitov AV, Ergesheva EV, Boichuk AV, Sevbitova MA. Experience of treatment of aphthous lesions of oral mucosa by preparations on the basis of collagen and digestase. Asian J Pharm 2018;12S1:284-7.

8. Evstratenko VV, Sevbitov AV, Platonova VV, Selifanova EI, Dorofeev AE. Distinctive features of 
crystallization of mixed saliva in patients taking heroin and methadone. Clin Lab Diagn 2018;63:223-7.

9. Utyuzh AS, Yumashev AV, Mikhailova MV. Spectrographic analysis of titanium alloys in prosthetic dentistry. J Glob Pharm Technol 2016;8:7-11.

10. Platonova VV, Sevbitov AV, Shakaryants AA, Dorofeev AE. Experimental and clinical substantiation of treatment of patients having odontogenous phlegmons of maxillofacial region with use of preparation dalargin in complex therapy. Clin Lab Diagn 2018;63:293-6.

11. Sevbitov AV, Platonova VV, Mironov SN, Dorofeev AE, Pustokhina IG. Experimental substantiation of the bactericidal effect of sodium hypochlorite on the microflora of a purulent wound with odontogenic phlegmons of the face and neck. Indo Am J Pharm Sci 2018;5:1635-37.

12. AkhmetshinEM, MorozovIV, PavlyukAV, Yumashev AV, Yumasheva NA, Gubarkov SV. Motivation of personnel in an innovative business climate. Eur Res Stud J 2018;21:352-61.

13. Borisov VV, Sevbitov AV, Poloneichik NM, Voloshina IM. Use of vector patterns for manufacturing of individual protective dental splints by method of thermoforming. Indo Am J Pharm Sci 2018;5:697-9.

14. Borisov VV. Using ultraviolet containers for storage and transportation of mouthguards. Indo Am J Pharm Sci 2018;5:1322-6.

15. Gopikrishna V, Pradeep G, Venkateshbabu N. Blackwell publishing ltd assessment of pulp vitality: A review. Int J
Paediatr Dent 2009;19:3-15.

16. Naik PN, Kiran RA, Yalamanchai S, Kumar VA, Goli S, Vashist N. Acupuncture: An alternative therapy in dentistry and its possible applications. Med Acupunct 2014;26:308-14.

17. Bukhtoyarov OV, Samarin DM. Psycho-immunological rehabilitation of advanced cancer patients with psychogenic medical history. Int $\mathrm{J}$ Med Med Sci 2013;5:489-502.

18. Petrovic D, Vujkov S, Petronijevic B, Sarcev I, Stojanac I. Examination of the bioelectrical activity of the masticatory muscles during angle's Class II division 2 therapy with an activator. Vojnosanit Pregl 2014;71:1116-22.

19. Rosén HI, Bergh IH, Lundman BM, Martensson LB. Patients' experiences and perceived causes of persisting discomfort following day surgery. BMC Nurs 2010;9:16.

20. Appukuttan DP. Strategies to manage patients with dental anxiety and dental phobia: Literature review. Clin Cosmet Investig Dent 2016;8:35-50.

21. Maximo DA Costa RS, Ribeiro SD, Cabral ED. Determinants of painful experience during dental treatment. Rev Dor São Paulo 2012;13:365-70.

22. Rash JA, Prkachin KM, Campbell TS. Observer trait anxiety is associated with response bias to patient facial pain expression independent of pain catastrophizing. Pain Res Manag 2015;20:39-45.

Source of Support: Nil. Conflict of Interest: None declared. 